\title{
ANTI-INTELECTUALISM0, NEOCONSERVADORISMO E REACIONARISMO NO BRASIL CONTEMPORÂNEO: 0 MOVIMENTO ESCOLA SEM PARTIDO E A PERSEGUIÇÃO AOS PROFESSORES
}

\author{
Bruno Antonio Picoli (UFFS)* \\ https://orcid.org/0000-0001-6831-2199 \\ Samuel Mânica Radaelli (IFPR)** \\ https://orcid.org/0000-0002-3343-8338 \\ Anderson Luiz Tedesco (Unochapecó)*** \\ https://orcid.org/0000-0002-7425-1748
}

\section{RESUMO}

Este artigo discute, em sua problemática, a possibilidade de estabelecer uma relação entre o anti-intelectualismo reacionário que condenou Sócrates à ingestão de cicuta na Grécia e a atual perseguição aos professores empreendidas por movimentos como o Escola Sem Partido (MESP). Para tanto, foi realizada uma pesquisa, de natureza qualitativa, envolvendo estudos bibliográficos. A análise evidencia que o Movimento Escola Sem Partido está enraizado em valores religiosos fundamentalistas, apoiado e fortalecido por partidos, instituições e líderes religiosos alinhados ao neoconservadorismo. Conclui-se que o anti-intelectualismo denunciado por Sócrates sempre esteve presente ou adormecido na tradição ocidental. Precisamente no caso brasileiro, o Movimento Escola Sem Partido assumiu características de uma radicalização da tendência anti-intelectual que se projeta sobre a cultura e a educação e direciona para os professores e professoras seu mais perverso reacionarismo.

Palavras-chave: Anti-intelectualismo. Educação. Escola Sem Partido. Neoconservadorismo. Reacionarismo.

\section{ABSTRACT}

\section{ANTI-INTELLECTUALISM, NEOCONSERVATISM AND REACTIONARYISM IN CONTEMPORARY BRAZIL: THE UNPOLITICAL SCHOOL MOVEMENT}

\footnotetext{
Doutor em Educação pela Pontifícia Universidade Católica do Rio Grande do Sul (PUC/RS). Professor da Universidade Fede ral da Fronteira Sul (UFFS) - Campus Chapecó. E-mail: bruno.picoli@uffs.edu.br

** Doutor em Direito pela Universidade Federal de Santa Catarina (UFSC). Professor do Instituto Federal do Paraná (IFPR) Campus Palmas. E-mail: samuel.radaelli@ifpr.edu.br

*** Doutor em Filosofia pela Pontifícia Universidade Católica do Paraná (PUC/PR). Professor da Universidade Comunitária da Região de Chapecó (Unochapecó). E-mail: anderson.tedesco@unochapeco.edu.br
} 


\section{AND THE PERSECUTION AGAINST TEACHERS}

This paper discusses, in its problematic, the possibility of establishing a relationship between the reactionary anti-intellectualism that condemned Socrates to ingesting hemlock in Greece and the current persecution against teachers undertaken by movements such as Unpolitical School Movement (USM). For that, a qualitative research was carried out, involving bibliographic studies. The analysis shows that the Unpolitical School Movement is rooted in fundamentalist religious values, supported and strengthened by parties, institutions and religious leaders aligned with neoconservatism. It follows that the anti-intellectualism denounced by Socrates has always been present or dormant in the Western tradition. Precisely in the Brazilian case, the Unpolitical School Movement took on the characteristics of a radicalization of the antiintellectual tendency that projects itself on culture and education and directs its most perverse reactionaries to teachers.

Keywords: Anti-intellectualism, Education, Unpolitical School Movement, Neoconservatism, Reactionary.

\section{RESUMEN}

\section{ANTIINTELECTUALISMO, NEOCONSERVADURISMO Y REACCIONISMO EN EL BRASIL CONTEMPORÁNEO: EL MOVIMIENTO DE LA ESCUELA SIN PARTIDO Y LA PERSECUCIÓN DE LOS MAESTROS}

Este artículo analiza, en su problemática, la posibilidad de establecer una relación entre el antiintelectualismo reaccionario que condenó a Sócrates a la ingestión de cicuta en Grecia y la actual persecución de los maestros llevada a cabo por Movimientos como la Escuela Sin Partido (MESP). Por lo tanto, se realizó una investigación de carácter cualitativo, con estudios bibliográficos. El análisis muestra que el Movimiento Escuela Sin Partido está enraizada en valores religiosos fundamentalistas, apoyados y fortalecidos por partidos, instituciones y líderes religiosos alineados con el neoconservadurismo. La conclusión es de que el antiintelectualismo denunciado por Sócrates siempre ha estado presente o latente en la tradición occidental. Precisamente en el caso brasileño, el Movimiento Escuela Sin Partido asumió las características de una radicalización de la tendencia anti intelectual que se proyecta en la cultura y la educación y dirige su reaccionismo más perverso a los maestros.

Palabras clave: Antiintelectualismo. Educación. Escuela sin Partido. Neoconservadurismo. Reaccionarismo.

\section{Introdução}

$\mathrm{Na}$ aurora do século IV a.C., Sócrates foi acusado, julgado e condenado à morte por um tribunal conduzido pelo rei de Atenas com 501 jurados. A acusação, apresentada por Meleto, um poeta sem expressividade, Lícon, um retórico obscuro, e Anito, um dos líderes da democracia ateniense, afirmava que Sócrates recusava o culto devido aos deuses do Estado e, com isso, pervertia a mocidade, levando-os a não respeitar a autoridade paterna (ATAÍDE, 2017). 0 próprio Anito era pai de um dos discípulos do filósofo e era com frequência 
indagado publicamente pelo filho a respeito de suas crenças (SALLES, 2019). As acusações eram, então, de ateísmo e subversão (ATAÍDE, 2017). 0 julgamento de Sócrates é o primeiro grande registro da perseguição contra um intelectual, da recusa em questionar as coisas dadas, do desejo de fazer das novas gerações o espelho das antigas. É provavelmente, também, a primeira manifestação de um reacionarismo organizado: mesmo após sua enfática defesa no Aerópago (PLATÃO, 2017), Sócrates foi condenado. Os bons homens da cidade não podiam conviver com alguém que os questionava no íntimo, que os provocava a reconhecer a própria ignorância, como o próprio Sócrates fazia com relação à sua.

Passaram-se alguns séculos entre o julgamento de Sócrates e o contexto histórico contemporâneo. Entretanto, ainda é possível encontrar acusações, cada vez mais enfáticas, contra a atividade intelectual, inclusive em termos muito semelhantes às acusações contra o filósofo ateniense que foi julgado por questionar as crenças tradicionais e perverter a mocidade. A problemática dessa reflexão trata-se de pensar se é possível estabelecer uma relação, no discurso e nas práticas, entre o anti-intelectualismo reacionário que condenou Sócrates à ingestão de cicuta e a atual perseguição àqueles que realizam atividades que têm por características não aceitar o mundo como ele se apresenta, ou seja, contra aqueles que procurar retirar o véu de Maia e desafiam seus contemporâneos a fazer o mesmo. Perseguindo essa resposta, o artigo, em seu constructo teórico, delineia-se em seis momentos: a) o primeiro se propõem analisar o anti-intelectualismo como tendência na tradição ocidental; b) o segundo trata as formas de ação ou os tentáculos do neoconservadorismo; c) o terceiro, as relações entre instituições e seus afluentes políticos; d) o quarto momento evidencia o anti-intelectualismo alinhado ao neoconservadorismo; e) o quinto trata de pensar no Movimento Escola Sem Partido como uma manifestação do anti-intelectualismo organizado; e, por fim, f) o antiintelectualismo do MESP como perseguição aos professores. Em tal organização metodológica, a reflexão assume características de natureza qualitativa, envolvendo estudos bibliográficos. Se evidencia no artigo uma tendência anti-intelectual como caraterística da formação do caráter da civilização ocidental, que oscila entre manifestações de maior força e organização e de menor influência, e que, no caso brasileiro e no campo da educação, o MESP é uma manifestação radical do anti-intelectualismo organizado. Mobilizado por grupos neoconservadores reacionários, sustenta que há uma ordem natural no modo como o mundo está disposto, assim como há uma ordem natural no desenvolvimento humano, tanto físico quanto psíquico e social. Reage, por meios lícitos e não lícitos, contra todos aqueles que questionam a sua "verdade". A exemplo de Meletos modernos, afirmam-se preocupados com a perversão da mocidade, com a influência dos "mestres" sobre os "discípulos" ou, em termos pós-modernos, dos professores sobre os alunos, com o questionamento do poder familiar, com o que denominam de "doutrinação". Ainda, como Meletos pós-modernos, perseguem professores que põem essa verdade em questão e, embora não possam condenar à morte seus perseguidos, esforçam-se em censurá-los, constrangê-los e em matar suas reputações.

\section{A tendência anti-intelectual na Tradição Ocidental}

O julgamento de Sócrates e sua condenação pela cidade foi divisor de águas na abordagem filosófica clássica, trata-se da desconfiança dos filósofos com relação à política (ARENDT, 2016). A partir disso, a reflexão recai sobre o lugar do intelectual na sociedade. A alegoria da caverna, de Platão, escrita por volta de 386 a. C., retrata o próprio julgamento ocorrido poucos anos antes. No diálogo, pela boca de Sócrates, Platão provoca:

Agora imagina a maneira como segue o estado da nossa natureza relativamente à instrução e 
a ignorância. Imagina homens numa morada subterrânea, em forma de caverna, com uma entrada aberta à luz; esses homens estão aí desde a infância, de pernas e pescoço acorrentados, de modo que não podem mexer-se nem ver senão o que está diante deles, pois as correntes os impedem de voltar a cabeça; a luz chega-lhes de uma fogueira acesa numa colina que se ergue por detrás deles; entre o fogo e os prisioneiros passa uma estrada ascendente. Imagina que ao longo dessa estrada está construído um pequeno muro [...] ao longo desse pequeno muro, homens que transportam objetos de toda espécie [...] Glauco - um quadro estranho e estranhos prisioneiros. Sócrates - Assemelham-se a nós. (PLATÃo, 2000, p. 225).

Na alegoria, o prisioneiro que consegue desvencilhar-se das correntes e evadir da caverna começa, lentamente, a conhecer a origem das projeções no interior da caverna. Com tempo e opróbio pode até olhar para o céu e encarar a luz do sol. Sente-se, então, incumbido do dever de retornar à escuridão da caverna e alertar aos demais que o que veem são sombras projetadas. Procura, portanto, educá-los (a provocação de Glauco a Sócrates era sobre a influência da educação na natureza humana). Contudo, os que lá estão não o compreendem, já que fala de coisas aparentemente fabulosas, de outro mundo. Os que lá estão, então, passam a entender como um terrível mal sair da caverna, como se o que regressa tivesse perdido o sentido da realidade. Em evidente referência ao julgamento de Sócrates, Platão induz que os que lá estavam o teriam matado pelo fato de pôr em suspeita a verdade daquilo que viam e que entendiam como "o mundo real", a "verdade". Não queriam experienciar o doloroso caminho que implica o pensar. Para Turchi (2003, p. 18) "a alegoria significa diretamente e sua razão de existência é transmitir um sentido". A alegoria platônica não se isola na sua temporalidade, trata-se, outrossim, de uma compreensão de nossa época histórica, cujas raízes estão constituídas na barbárie cultural, no reacionarismo: o exemplo dos indivíduos que vivem na condição de prisioneiros na alegoria da caverna, reacionários às dúvidas lançadas por aquele que regressa na condição de filósofo, de intelectual.

Como um desdobramento de longo prazo dessa tensa relação entre os intelectuais, a moral dominante e o poder constituído, encontra-se em Kant (2012, p. 153), em seu ensaio de 1784 , no qual busca responder à provocação " 0 que é o esclarecimento?", uma clara preocupação em tranquilizar o imperador Frederico II sobre os perigos, para o governo, das atividades do intelectual, daquele que se liberta da tutela autoimposta, que supera a preguiça e a covardia e tem a "coragem de usar a própria mente", daquele que se desvencilha das correntes e sai da caverna, em termos platônicos.

Kant (2012), adepto que era da perspectiva iluminista do progresso, não compreendia (ou omitia para torná-la viável, ou melhor, para oferecer ao intelectual um espaço de segurança) uma caraterística que é fundamental na atividade intelectual: ela é, sempre, perigosa. Em Arendt (2017), numa obra em muito inspirada pelas reflexões kantianas, encontra-se a afirmação de que não existe um tipo de pensamento perigoso, como se fosse possível estabelecer, então, uma margem de segurança, um limite, outrossim que todo pensamento é perigoso, haja vista que, ao pensar, o que está dado é posto em questão, assim como são postos em dúvida os próprios fundamentos do pensamento que questiona.

A denúncia do anti-intelectualismo na tradição cultural ocidental é também encontrada nos escritos de Nietzsche publicados entre 1872 e 1874. Na conferência "Sobre o Futuro dos Nossos Estabelecimentos de Ensino", de 1872, afirma que se verificam duas tendências dominantes na cultural educacional de seu tempo: a "de estender tanto quanto possível a cultura" e a "de reduzi-la e enfraquecê-la" (NIETZSCHE, 2011, p. 53). Segundo ele, a primeira tendência assegura uma cultura de massa que deve ser levada a todos os círculos, enquanto a segunda constitui-se em submissão às regras das políticas de Estado. Precisamente, porque o resultado disso é catastrófico para a formação dos espíritos livres na medida em 
que não formam para a vida. Na segunda consideração extemporânea, de 1873, reitera isso na denúncia da preocupação dominante em preservar a tradição e como ela opera como um fardo que impede que o tempo seja experimentado, ou seja, que se insira nele algo de novo. Sublinha o engessamento das práticas pedagógicas no seu tempo, demonstrando como tal processo leva à pobreza cultural. Por isso, Dias (1993) considera que as críticas de Nietzsche são direcionadas ao papel do Estado, que não se preocupava com uma educação para libertação, mas sim em ocupar com louvor as funções do nacionalismo, "a seus olhos, nada tem de próprio, sendo desprovida de sentido: sem substância, sem meta, uma mera opinião pública" (DIAS, 1993, p. 40), Nietzsche, nesses escritos, ainda se mostra esperançoso de que "homens sérios, a serviço de uma cultura inteiramente renovada e purificada e num trabalho comum, se tornarão os legisladores da educação rotineira - da educação que leva a esta cultura" (NIETZSCHE, 2011, p. 54). A educação seria o processo de criação de tais personagens que se posicionassem contrários ao anti-intelectualismo. Quase um século antes, Kant (2012, p. 146) chama essas pessoas de "pensadores independentes", ou seja, aqueles que "depois de sacudir o jugo da imaturidade, difundirão o espírito de uma estimativa razoável de seu próprio valor e da vocação de cada homem de pensar por si". Nietzsche constatou em Schopenhauer esse pensador. Para ele, "através de Schopenhauer, podemos nos educar contra o nosso tempo, porque temos, graças a ele, a vantagem de conhecer verdadeiramente este tempo" (NIETZSCHE, 2011, p. 191). Contudo, para o filósofo, Schopenhauer era exceção. Tal diagnóstico sobre a cultura e a educação revelou-se como uma profunda preocupação com o anti-intelectualismo dominante na formação pedagógica.

As preocupações sobre a força do anti-intelectualismo, presente em Platão, Kant e Nietzsche, não estão distantes daquelas que nos afligem atualmente. Adorno (1995), em
Educação após Auschwitz, de 1965, afirma que o que torna terrivelmente difícil enfrentar o anti-intelectualismo, e seus correlatos contemporâneos, é que ele não é uma exceção, algo que ocorre por fora do desenvolvimento civilizacional; ao contrário, "encontra-se vinculada ao conjunto da civilização" (ADORNO, 1995, p. 133), a corrói por dentro e, quando organizada, reage e procura destruir os ensaios de sua superação. No Brasil contemporâneo o anti-intelectualismo encontra-se organizado e, além disso, propositivo, especialmente no campo educacional. Os projetos de lei do Movimento Escola Sem Partido (MESP) e para a regulamentação da Educação Domiciliar, programa de militarização de escolas públicas de Educação Básica, além do combate à produção didática (mas não só), procuram problematizar questões étnico-raciais, de gênero etc. 0 anti -intelectualismo organizado, mobilizado por segmentos neoconservadores, procura criar um espírito de conformidade e submissão na forma de pensar que faz com que seja possível que reincidamos nas terríveis experiências produzidas pelo anti-intelectualismo de outros tempos, ou seja, opera para que não experimentemos o nosso tempo como um "tempo nosso".

Na próxima seção discute-se as características do neoconservadorismo brasileiro, a manifestação contemporânea do anti-intelectualismo que engendrou propostas de reforma educacional como as do MESP.

\section{neoconservadorismo, sua mensagem explícita e sua a prática implícita}

O discurso neoconservador se declara como uma prática orientada pela busca da manutenção das "conquistas civilizacionais" e/ou da "ordem natural das coisas," as quais estariam ameaçadas pela ação de forças corruptoras destes dois esteios da sociedade. Embora em muitos casos essa afirmação possa ser franca (CALLEGARIS, 2019), o neoconservadorismo 
pratica um conjunto de atitudes voltadas para a defesa das diferenças sociais em uma perspectiva hierárquica, pela qual as diferenças devem expressar níveis de superioridade e inferioridade, tais níveis orientam política e culturalmente as sociedades. Associada a isso, a defesa da desigualdade como um elemento natural ou inexorável da existência humana. Com essa prática o neoconservadorismo reafirma a perversidade como regra histórica, como norma naturalizada.

O neoconservadorismo se apresenta como anti-ideológico, mas na verdade se firma como contrautópico, pois "Conservadorismo não é defender a tradição, é resistir ao surgimento de novas tradições" (COSTA, 1995, p. 41). É a resposta conservadora aos movimentos progressistas que faz com que o conservadorismo alcance o estágio reacionário. A resposta política contra aqueles que lutam pela transformação ou por revolução leva o neoconservadorismo aos seu estágio mais ativo, a reação: o reacionário é o militante do conservadorismo que age para combater, por meio lícitos ou não, os agentes e as políticas de ruptura da hegemonia vigente, de modo a frustrar as ações socialmente transformadoras. 0 reacionário geralmente não se vê na defesa de um ideário político, mas em geral manifesta-se em defesa de valores vagos, como ordem, família e costumes. Assumir-se reacionário é algo que requer uma roupagem, ou camuflagem, teórica mais propositiva, confundindo-se com noções progressistas, por isso a "reação à brasileira" geralmente se apresenta em rotulagem "liberal", mas de um "liberalismo" que aposta na liberdade do mercado e não do indivíduo. Há, inclusive, uma síntese estranha expressa em um slogan: "liberal na economia, conservador nos costumes", existindo inclusive movimentos que se declaram "liberais-conservadores". Diante da óbvia contradição, cabe lembrar Levinas (2016, p. 51) quando afirma que "uma contradição lógica não é capaz de julgar um acontecimento concreto", assim, tal posição se manifesta com força, a despeito do absurdo que representa. Como afirma Arendt (1973, p. 333), "é justamente esse absurdo que faz com que uma ideia se torne perigosamente poderosa, desde que amparada pela propaganda. Propaganda, hoje, que prescinde dos meios tradicionais, das mass media". A promessa de lutar para manter "conquistas civilizatórias" se esvai quando se lançam ao ataque dos avanços no plano ético-político, como quando da objeção aos direitos humanos e aos ideais de emancipação.

O neoconservadorismo, em sua face reacionária, luta para manter aquilo que o processo civilizatório revelou iníquo e se pôs a enfrentar. Não se resume a uma postura mantenedora, é mais que a opção pelo que está posto, é contra o novo que se quer construir, embora a defesa da experiência vivida seja, indiscutivelmente, um elemento importante e agregador de adesões. 0 neoconservadorismo está associado, também, a uma desconfiança fundamental, que se apresenta como uma característica determinante; esta desconfiança se manifesta ante "a ideia de que segundo a qual a sociedade pode ser objeto de aplicação de um plano" (LILA, 2018, p. 156), de que está em curso uma grande conspiração global e de que os intelectuais e artistas são cúmplices. Essa convicção serve para revestir a prática reacionária de um caráter moralmente superior e transcendente. Por ela, o reacionário autoriza-se a se autointitular "cidadão de bem". A invocação do moralismo é sintomática nos perversos, afinal o moralismo trata de estabelecer a maldade de outrem por essência, a qual se expressa em gostos e atitudes. Ao estabelecer o caráter negativo do outro, o moralista cria um dístico de bem e mal, que serve à prévia absolvição das condutas próprias, por piores que elas sejam. Com isso, a maldade presente naquilo que o outro é cumpre a função de um álibi para justificar as atitudes próprias. Tal era a perversidade da ação nazista contra os judeus durante a execução da solução final, quando Himmler, em discurso às tropas SS, afirmava o mantra que deveria ser inculcado pelos soldados: "Que coisas horríveis eu tive de ver na 
execução dos meus deveres, como essa tarefa pesa sobre meus ombros!" (ARENDT, 1999, p. 122). Não se nega a maldade praticada, tão só afirma-se ser necessária.

0 "cidadão de bem", figura que não possui antônimo, talvez porque em face do "cidadão de bem" exista apenas o não cidadão. Essa autointitulação expressa a força da mentira e do cinismo, do autoengano na configuração política das sociedades. 0 limite disso foi o que Arendt (1999, p. 62) afirmou ser "a característica fundante do caráter alemão durante a primeira metade do século 20: o autoengano". A "cidadania do bem", como autoproclamação, é a afirmação da superioridade da própria condição ante aquele que não é e não pode ser. É a negação da alteridade. Afinal, quem é o que não está no rol de autoproclamados cidadãos de bem? Quem é o mau? Assim, será rotulado pelo que faz ou pelo que é? A resposta revela o conjunto de preconceitos e perversidades que as assimetrias que moldam nossa sociedade produzem. A maldade factual ou potencial é o álibi (quase) perfeito da perversidade. 0 "cidadão de bem" é o guardião da perversidade enrustida na defesa da ordem e no combate à dúvida, ou melhor, aos que duvidam.

\section{Afluentes políticos do neoconservadorismo: fascismo e neoliberalismo}

Mais que uma corrente teórica, o fascismo se caracteriza como um comportamento político, em geral pautado por convicções não fundadas racionalmente. Dentre as atitudes características do fascismo, destacam-se o ódio como reação à diferença, à divergência e à dissidência; além do culto a uma figura política ou agremiação de forma irracional, sendo indiferentes à viabilidade das soluções propostas. Além disso, os movimentos fascistas fazem uma aposta redentora na violência (KONDER, 1977, p. 21). Desencadeia-se uma compreensão invertida das posições sociais: as vítimas passam a figurar como opressores. Cria-se a figura do inimigo público, a qual pode ser encarnada nas múltiplas figuras indesejadas (negros, LGBTs, depauperados, petistas, tucanos, comunistas, bandidos, corruptos etc.). Nesta mesma senda, faz uma aposta cognitiva na divisão por dísticos incomunicáveis que fortalecem o combate maniqueísta entre bem e mal (ex: a luta do "cidadão de bem" contra o "vagabundo"). 0 resultado desse combate deve ser a eliminação do inimigo público, afinal ele não pode ser visto como um membro do povo.

Verifica-se também uma postura de simplificação das relações sociais, com o combate aos fatores que revelam a complexidade social. A crença na autoevidência da sociedade, a qual pode ser compreendida sem teorias ou conceitos, em uma postura anti-intelectual que vê com desprezo e ódio a atitude reflexiva, canalizando sua raiva na direção das figuras pensantes da sociedade (ex: combate à doutrinação nas escolas, luta para desacreditar a História e os historiadores). No âmbito cognitivo revela-se uma postura anti-intelectual, com a construção de fundamentos a partir de argumentos não ontológicos, os quais ganham força por meio das estratégias de replicação em massa propiciadas por tecnologias e recursos estéticos inovadores.

Nas últimas décadas, a manifestação de um pensamento neoliberal, no qual a democracia é um valor apenas instrumental ante a liberdade econômica (BOBBIO, 1997), tem incidido sobre a orientação político-econômica de muitos países atingidos pela crise do Estado social, os quais, em muitos casos, têm dificuldade de financiar suas políticas de bem-estar, especialmente em razão do processo de financeirização da economia. Para Bercovici (2004, p. 327), o que caracteriza um estado de Exceção permanente é que "formalmente, vigoram os princípios democráticos, mas, na prática, são constantemente suspensos ou violados." Tal versão apoia-se na visão de Agamben (2004, p. 9), na qual o "estado de exceção passa a ser um paradigma de governo". Em tal configura- 
ção, os cenários de crises constantes levam a justificar práticas de exceptuação de direitos, bem como de retrocessos sociais, ações feitas distante do "povo soberano", pensadas originalmente como um conjunto de medidas diante de situações emergenciais que "justificam a excepcionalidade".

No tempo presente, revela-se, ainda mais clara, a frustração dos ideais políticos oriundos da modernidade que definiram o Estado como uma figura liberal, portadora de promessas de liberdade e apropriação popular do poder. Os apelos por mudança e a insatisfação política no Brasil deram vazão a um discurso de "nova política", as promessas de mudança foram por muitos sintetizadas em um mantra largamente recitado, tido como reposta aos grandes impasses da nossa sociedade: "liberal na economia, conservador nos costumes". Com este slogan definiu-se o espírito daqueles que, imbuídos de personalidade mistificadora, declararam-se capazes de resolver de forma rápida os problemas da sociedade, especialmente a corrupção e a ameaça comunista. Para eles, as causas dos problemas sociais podem ser explicadas seguindo a mesma fórmula de simplificação que desqualifica quem é vítima de uma realidade social perversa. 0 pobre, na mentalidade neoliberal-neoconservadora, é o responsável pelo seu próprio fracasso, pois não se esforçou o suficiente para competir por um lugar no mercado (McLAREN; FAHADMANDPUR, 2001).

No entanto, tal inovação política é só um discurso. Aqueles que o repetem dão margem ao velho adágio "aquilo do que mais fala é o que mais falta", ou seja, a "nova política" é a nova roupagem de ideários retrógrados de múltiplas faces, especialmente os fascistas. A contradição é óbvia: como pode ser nova uma aposta política no conservadorismo dos costumes? A relação entre (neo)liberalismo e (neo)conservadorismo, no entanto, não é nova. A formação dos panoramas institucionais brasileiro e latino-americano já expressava essa inusitada síntese liberal-conservadora ainda no século XIX. O que reafirma a tendência anti-in- telectual de nossa tradição. Este contraditório pacto liberal-conservador deu-se em razão de que ambos os grupos tinham, inobstante suas enormes diferenças, muitos objetivos em comum. Seu principal ponto de discórdia se dava nos temas acerca dos costumes, pois enquanto uns queriam o estabelecimento de uma ordem favorável ao império da religião, outros defendiam - por diversas razões - uma ordem institucional mais aberta. Liberais e conservadores apresentavam diferenças, também, em relação ao nível de concentração da autoridade nacional e política. Para além dessas discrepâncias, houve um enorme campo de convergência: tanto liberais como conservadores tinham interesse na defesa da propriedade, ameaçada pelas demandas crescentes de grupos políticos, até então excluídos e cada vez mais exigentes. Neste sentido, ambas as colorações políticas se mostravam temerosas das consequências do acesso ativo das massas ao sistema de tomada de decisões (GARGARELA, 2005). As recentes conquistas de grupos até então invisibilizados, como LGBTs, negros, mulheres etc., aglutinou esses setores reacionários na sociedade brasileira.

Diferente do liberalismo no século XIX, que buscava aparentar a adesão a um processo civilizatório e modernizador, com vistas a ocultar o elitismo e a brutalidade das relações sociais, a invocação do "liberalismo", agora, é francamente restritiva: "liberais, só na economia", o que significa a sujeição da sociedade por meio de suas instituições aos ditames do mercado. Invoca-se o liberalismo acentuando a promessa de liberdade feita por ele séculos atrás; contudo, tal promessa se restringe ao mercado, nisso se desenha o neoliberalismo, como a soberania do mercado com máxima liberdade para os fortes servirem-se dos fracos (GUILHERME; PICOLI, 2019). 0 discurso de liberdade, à medida que livra os atores dominantes de qualquer limitação civilizatória, passa a ser contido para que não chegue a outras esferas da sociedade.

Restringir a liberdade à esfera do mercado, impedindo que esse discurso atinja os corpos, 
é justamente o papel do neoconservadorismo atual. Ser conservador nos costumes significa reforçar a manutenção das estruturas de poder de uma sociedade, em especial na defesa do patriarcado, concepção fundamental para as estruturas autoritárias, especialmente as fascistas, pois:

Numa sociedade fascista, o líder da nação é análogo ao pai de família patriarcal tradicional. O líder é o pai da nação, e sua força e poder são a fonte de sua autoridade legal, assim como a força e poder do pai da família no patriarcado supostamente são a fonte de sua suprema autoridade moral sobre seus filhos e esposa. 0 líder provê a nação, assim como na família tradicional o pai é o provedor. A autoridade do pai patriarcal deriva de sua força, e a força é o principal valor autoritário. Ao apresentar o passado da nação como um passado com uma estrutura familiar patriarcal, a política fascista conecta a nostalgia de uma estrutura autoritária hierárquica organizadora central, que encontra sua mais pura representação nessas normas. (STANLEY, 2018, p. 22).

A defesa da liberdade para o mercado, que contrasta com o aprisionamento do corpo no âmbito da sexualidade, da identidade e das relações de trabalho. Em resumo, corpos ao dispor do poder e do lucro. Em um país forjado em bases escravocratas nada disso pode ser chamado de "nova política".

\section{Anti-intelectualismo: conforto espiritual e cognitivo do neoconservadorismo}

Dar razão a quem manda é a mais confortável ação do entendimento humano; dela decorre a prática tão comum de catar seletivamente fatos excepcionais para fundamentar conclusões estabelecidas previamente, ou seja, a conclusão não como decorrência do pensamento, mas como meta, a qual o percurso argumentativo deve chegar. Se a fé conforta, por que não colocar a profissão de fé como prática que orienta todas as escolhas ante a complexidade do mundo? A constatação da impossibilidade de as coisas serem como parecem se torna asfixiante ao neoconservador: de um lado, a resignação não é mais autorizada, principalmente pelos coachings, por outro, a ruptura com as estruturas que estabelecem estas contradições é proibida. Daí parte-se para a negação científica, para a manipulação dos fatos, fazendo a aposta no absurdo que conforta e não acrisola. Ao invés de libertar-se, apertam-se as correntes para que a caverna não deixe de ser a única possibilidade.

Quando denunciada a precariedade das respostas apriorísticas aos graves problemas que a humanidade enfrenta, o que se segue é a busca por uma saída simples, rápida e de fácil implementação, que cumpra a função de não responder ao problema posto em questão, mas de animar a ilusão contendora daqueles cujo rigor dos problemas abranda com a esperança, ou a ilusão, de poder construir uma resposta individual ou coletiva que seja rápida, simples e sem radicalidade. A ideia de que a reposta aos problemas sociais se faz na proporção de tempo e da complexidade em que se deu a construção desses problemas é inaceitavelmente desconfortável. A busca por conforto intelectual vai além da construção de respostas simples para problemas graves; a realidade é tão complexa que a inescrutabilidade das situações históricas estruturais que a compõem leva à construção de falsos dilemas ou à supervalorização dos efeitos ocultando-se as causas. Na mesma lógica, se é possível escolher os produtos que se adaptam ao gosto, escolha delimitada pelo custo, por que não escolher as ideias de acordo com a conveniência, delimitada pelo dispêndio cognitivo que cada um pode dar? Sendo sempre o mais econômico possível, levando em conta os ditames da razão instrumental.

As ideias deveriam orientar as escolhas, contudo num processo anti-intelectual de autorreferenciação das atitudes, as ações buscam ideias como álibis para que não se pareçam desarrazoadas. Escolhe-se ideias como escolhe-se bens de consumo: orientando-se para o bem-estar pessoal, para o conforto. Assim, 
seleciona-se ideias que não provocam o (re) pensar das convicções. Em sentido oposto, nega-se ou combate-se as ideias "novas" que questionam as convicções sedimentadas. No neoconservadorismo corrente, tanto a aversão quanto a adesão teórica (ou ideológica) se dão em um terreno de passionalidade, idealização e voluntarismo que soterram duas das mais relevantes potencialidades do ser humano: o pensamento e a sensibilidade. Firma-se, assim, a cognição por apetência; por ela conhecer e ignorar, são atos que se equivalem na teia de anseios e ilusões que determinam as atitudes e reflexões, ou a falta de ambas; conhecer e desconhecer por conta da comodidade ou aversão impossibilita a infidelidade à atitude colaborativa que a manutenção do status quo demanda. É neste cenário que floresce a aversão à ciência, ao pensamento e aos cientistas. No Brasil contemporâneo, o neoconservadorismo (com seus afluentes políticos) anti-intelectual organizouse em movimentos propositivos. No campo da educação ganhou destaque nos últimos anos o Movimento Escola Sem Partido (MESP), sobre o que se dedica a seção a seguir.

\section{Movimento Escola Sem Partido como manifestação do anti-intelectualismo organizado}

A manipulação de fatos, a negação da ciência e do debate, a recusa em tocar em temas que produzam algum tipo de desconforto, o enquadramento da realidade nos limites de um discurso moralista e simplificador e reprodutor de uma ideia preestabelecida de "verdade", o que caracteriza o anti-intelectualismo, se manifesta nos mais diversos espectros políticos. Arendt (1973) afirma que uma das principais características dos movimentos de caráter totalitário é a manipulação pela propaganda que subverte ciência em ideologia e ideologia em verdade. Essa autora, em sua análise, afirma que tanto a extrema-direita quanto a extrema-esquerda incorrem nisso. Ambos, a partir de diferentes objetivos e visões de mundo, assim como a partir de diferentes práticas, procuraram estabelecer uma verdade a partir da manipulação e da negação de fatos, ideias, valores etc. que a colocava em xeque (ARENDT, 1973). Passadas as experiências alemã e stalinista em suas dimensões radicais, não significa que os valores totalitários, anti-intelectuais, tenham sido superados. Adorno (1995), em 1961, afirma que um dos grandes problemas das democracias modernas - o que, embora não as desqualifique, ao contrário, exige sua vigilância constante - é que elas possibilitam brechas para que grupos totalitários se articulem e usem dos dispositivos das democracias representativas para reapresentar-se ao público com um verniz de renovação, e, mesmo, de democracia. Não de democracia como direitos, mas como vontade da maioria. Em Arendt (1973) e Adorno (1995) encontramos o alerta da possibilidade, sempre presente, de reingressarmos, às vezes, alegremente, em regimes totalitários, em tempos sombrios. Essa advertência exige uma postura vigilante e corajosa de não silenciar frente ao avanço, mesmo que pelas vias reconhecidas e formais da democracia, do anti-intelectualismo.

Embora tenha se afirmado que o anti-intelectualismo se verifica em quase todos os espectros da política, especialmente nos seus extremos, o que se afirma aqui é que o Movimento Escola Sem Partido é uma manifestação do anti-intelectualismo organizado de feitio neofascista que apela a supostos valores tradicionais compartilhados pela maioria dos brasileiros (GUILHERME; PICOLI, 2018). Não se pretende adentrar aqui se de fato são valores compartilhados pela maioria, pois mesmo que o fossem isso não oferece razão às reivindicações do movimento, haja vista o caráter contramajoritário, constitucionalmente definido, da jovem democracia brasileira, ou seja, a defesa de direitos democráticos de minorias derrotadas por maiorias ocasionais (NUNES, 2019; SANTOS, 2019; SGARBOSSA et al., 2012). 
Marginal no debate político e educacional até 2014, quando da primeira apresentação de um Projeto de Lei sob sua influência na Câmera dos Deputados (BRASIL, 2014), o MESP ganhou projeção no cenário de polarização política que teve lugar no Brasil a partir de junho de 2013 e do processo eleitoral de 2014. A partir de então, foram apresentados às duas casas legislativas brasileiras, e a várias Assembleias Legislativas de Estados e Câmaras de Vereadores, projetos de lei inspirados no MESP. 0 próprio movimento, em seu site, disponibiliza anteprojetos de lei para vereadores, deputados estaduais e federais e senadores (ESCOLA SEM PARTIDO, 2020a). De acordo com Penna e Salles (2017), o MESP, que até 2014 limitava sua atuação na denúncia de supostos professores-doutrinadores, organizou, a pedido do então deputado estadual do Rio de Janeiro, Flávio Bolsonaro, suas ideias em um projeto de lei (do qual se desdobrariam os anteprojetos). Isso foi um importante passo na organização do MESP, pois, a partir de então, procurou por dentro corroer a democracia brasileira e se consolidar enquanto instituição.

Penna e Salles (2017) afirmam que o MESP mobiliza um discurso de base político-ideológica conservadora de caráter reacionário, ou seja, produz contrainvestidas em relação a alguns avanços ou possíveis avanços nos mais diversos campos: econômico, religioso, comportamental, político, social etc. Não se trata de uma exclusividade brasileira que, quando grupos até então invisibilizados conquistam algum espaço de visibilidade e, logo, direitos, grupos conservadores se mobilizem para reagir ao que afirmam ser uma deturpação da ordem e dos valores tradicionais, em outras palavras, do status quo. Em reflexão que também se voltou para o campo educacional, Apple (1993) afirma que foi a partir dos resultados das políticas compensatórias aos negros norte-americanos, empreendida durante os anos 1980, que setores conservadores da sociedade norte-americana passaram a pressionar mudanças curriculares para as escolas dos
Estados Unidos. Essas mudanças atacavam a inserção nos programas escolares de debates decoloniais, do evolucionismo, do pluralismo democrático, afirmando que tais questões eram de foro íntimo (familiar) e, logo, não deveriam compreender parte do currículo escolar (estatal). Essa pressão se verificou especialmente nos debates para a formulação de uma Base Curricular Nacional para os Estados Unidos nos anos 1990. De forma semelhante, conforme Penna e Salles (2017, p. 14), o MESP propõe a

[...] defesa da família e de um certo arcabouço de valores, com ênfase numa orientação patriarcal e hetoronormativa; imposição de uma separação entre assuntos que podem ser abordados na escola e assuntos que só devem ser tratados no espaço privado do lar; desconfiança de instituições e agentes identificadas como promotoras de interesses estatais e governamentais - escolas e professores.

Como advertido por Adorno (1995), os grupos neofascistas não atuam apenas contra a democracia, mas por dentro da democracia: o cumprimento do rito, através da proposição de projetos de lei, é acompanhado por propaganda que visa angariar apoio popular. A escolha do nome, além disso, é um excepcional acerto do movimento. Ela manipula a concepção popular de "partido" como "partido político" e conduz à adesão massiva se apresentando como não ideológica, purista. Afinal, ninguém quer uma escola que esteja sob o domínio de um partido ou agremiação política. Contudo, o "partido" do MESP não se limita a isso. Defende uma escola que não toma partido pela ciência, que não toma partido pelos direitos humanos (estabelecidos em constituição, leis e tratados). Uma escola que não toma partido pela democracia, pelo debate de ideias e pela problematização de valores. Uma escola que não toma partido pela educação, afinal, a educação possui uma irrenunciável dimensão axiológica: educar é hierarquizar valores (BIESTA, 2017; SAVATER, 1998).

Afirmar que todas as opiniões têm o mesmo valor e que, portanto, a escola não deve 
discutir valores e concepções de mundo é uma radicalização do anti-intectualismo de caráter totalitário. 0 movimento insiste em afirmar que há uma grande conspiração, da qual participam intelectuais, universidades e escolas, para doutrinar crianças e jovens e desvirtuá-los dos valores admitidos (especialmente da família, da moral tradicional e da religião). Recorre, para isso, às opiniões correntes e capilarizadas pelos próprios apoiadores: "É fato notório que professores e autores de materiais didáticos vêm se utilizando de suas aulas e de suas obras para tentar obter a adesão dos estudantes à determinadas correntes políticas e ideológicas", além de incentivar que "adotem padrões de julgamento e de conduta moral - especialmente moral sexual - incompatíveis com os que lhes são ensinados por seus pais ou responsáveis" (ESCOLA SEM PARTIDO, 2020b). Embora reconheça que há também "doutrinadores" de direita, o MESP, que se diz não partidário, afirma que o impacto desses é mínimo, ao contrário da esquerda que, conforme sustentam, move uma grande conspiração global:

No Brasil, quem promove a doutrinação político -ideológica em sala de aula, de forma sistemática e organizada, com apoio teórico (Gramsci, Althusser, Freire, Saviani etc.), político (governos e partidos de esquerda, PT à frente), burocrático (MEC e secretarias de educação), editorial (indústria do livro didático) e sindical é a esquerda. (ESCOLA SEM PARTIDO, 2020c).

Esse discurso foi utilizado a todo tempo durante a campanha eleitoral para a presidência da República em 2018 pelo candidato vencedor, apoiador declarado do MESP (ESCOLA..., 2017). Durante uma entrevista concedida ao jornal de maior audiência no horário nobre, o candidato afirmou que "defendia as crianças em sala de aula". Na retórica, proteger as crianças em sala de aula significa proteger contra os professores. E, descumprindo as regras da entrevista, tentou mostrar ao público um livro supostamente utilizado em escolas públicas brasileiras para doutrinar as crianças a partir da reprodução de valores morais desvirtua- dos (ENTREVISTA..., 2018). A partir desse subterfúgio, um memorando-circular de 6 de fevereiro de 2020, da Secretaria de Educação de Rondônia, cujo governo é alinhado ao governo federal, recomendou o recolhimento imediato de obras literárias nacionais e internacionais por considerá-las com "conteúdos inadequados às crianças e adolescentes" (DOCUMENTO..., 2020). Dentre os autores a serem recolhidos estavam Machado de Assis, Euclides da Cunha, Mário de Andrade e Franz Kafka.

Ainda na entrevista supracitada, quando confrontado pelo entrevistador sobre a versão historiográfica sobre o Golpe Civil-Militar de 1964, afirmou: "deixa os historiadores pra lá" (ENTREVISTA..., 2018), e, em seguida, reafirmou sua "verdade" histórica. Isso nos remete à advertência de Arendt (1973) sobre as formas anti-intelectuais do totalitarismo, pelas quais as perspectivas fundadas em bases factuais, em fontes (como no caso da historiografia), em dados (como no caso do aquecimento global), em empiria (como no caso da teoria da evolução), são convertidas em mera opinião e, portanto, passíveis de contestação por qualquer outra opinião, mesmo que não fundamentada.

Os projetos do MESP que foram apresentados entre 2014 e 2016 na Câmara dos Deputados e no Senado Federal foram arquivados e retirado da pauta. Entretanto, isso não significou desmobilização, outrossim recrudescimento do movimento. Em 2019 foi apresentado à Câmara dos Deputados o Projeto de Lei no 246 (BRASIL, 2019). 0 novo projeto, além de incorporar em grande parte o que propunham os projetos anteriores e, assim como os anteriores, replicar quase em sua totalidade o anteprojeto oferecido pelo MESP, também dispõe, no Art. 7o, sobre a autorização de que as aulas de professores sejam gravadas por estudantes. Embora nas justificativas, que reproduzem exatamente as justificativas disponíveis no anteprojeto do MESP, tal medida não tenha por objetivo controlar os professores e sim garantir que os estudantes tenham o acesso ao conteúdo das aulas para melhorar 
seu desempenho e para que os pais tenham ciência do processo pedagógico vivenciado pelos filhos, fica evidente a predisposição em controlar, censurar e, eventualmente, punir os professores. Punição que pode se dar pela via jurídica ou pela publicização da aula, o que implica a criação de um tribunal moral permanente sem direito de justa e equivalente defesa. Na próxima seção se discute a perseguição perpetrada pelo movimento contra professores em específico e, como corolário, contra todos os que se envolvem efetivamente em educação.

\section{Anti-intelectualismo organizado como perseguição aos professores}

Como afirmado anteriormente, o MESP é uma manifestação do anti-intelectualismo organizado que tem nos professores um de seus inimigos eleitos (PENNA; SALLES, 2017). Em uma frente, os apoiadores do MESP atribuem aos professores, e tão somente a eles e elas, a responsabilidade pelo fracasso escolar e pela classificação brasileira em testes padronizados. Entretanto não é só isso: o MESP procura criminalizar a prática docente. 0 fundador e coordenador do MESP, o advogado Miguel Nagib, costuma enfatizar que o site mantido pelo MESP é o único em língua portuguesa dedicado exclusivamente ao combate à doutrinação nas escolas (ESCOLA SEM PARTIDO, 2020d). No site oficial do movimento encontra-se a afirmação de que o Movimento foi criado para dar a devida visibilidade ao problema, que supostamente atinge a maioria das escolas e universidade, da doutrinação, e que "o modo de fazê-lo é divulgar o testemunho das vítimas, ou seja, dos próprios alunos" (ESCOLA SEM PARTIDO, 2020e). Considerando que os alunos (não as crianças, mas "os alunos") são as vítimas, restam como agressores, violentadores, ou como o próprio Nagib afirmou em audiência na Câmara dos Deputados em 14 de fevereiro de 2017, abusadores ou estupradores, os pro- fessores e professoras (BRASIL, 2017). Com o objetivo, então, de "denunciar o doutrinador", em todas as abas do site do MESP está disponível um botão amarelo com os dizeres "Quero denunciar", antecedido pela chamada: "Se você ou seu filho foi ou está sendo vítima de algum militante disfarçado de professor, denuncie" (ESCOLA SEM PARTIDO, 2020f).

Penna e Salles (2017) afirmam que o discurso do MESP encontra ressonância porque habilmente mobiliza os medos cada vez mais comuns das pessoas nas sociedades modernas, especialmente de segmentos conservadores (aqui tomando-se conservador no bom sentido, afinal, deve-se querer conservar a dignidade das crianças, a segurança e a qualidade do crescimento). O MESP mobiliza medos antigos, produz novos e os difunde, em seguida oferece a solução. Conforme esses autores, "os professores tornam-se um inimigo palpável e facilmente localizável frente ao medo difuso de uma conspiração de esquerda" (PENNA; SALLES, 2017, p. 258). Na composição narrativa dos inimigos da família, da tradição, da infância, da moral etc., o MESP sustenta a existência de uma conspiração para desvirtuar a moral e instituir uma ditadura gay de orientação marxista (GUILHERME; PICOLI, 2018), da qual os professores são agentes infiltrados. Conforme o MESP: "A pretexto de transmitir aos alunos uma 'visão crítica' da realidade, um exército organizado de militantes travestidos de professores prevalece-se da liberdade de cátedra e da cortina de segredo das salas de aula para impingir-lhes a sua própria visão de mundo." (ESCOLA SEM PARTIDO, 2020e, grifo do autor). Por isso, Penna e Salles (2017, p. 257) afirmam que a adesão conquistada pelo movimento se deve ao fato de que toca

[...] em um tema onde as preocupações privadas e as questões públicas estão sobrepostas: o bem-estar das crianças e dos jovens. A princípio parece absurdo imaginar no que os professores podem ameaçar o bem-estar dos jovens, mas o MESP esforça-se em representar os professores como agentes que se aproveitam da inocência das crianças para explorá-las. Essa 
estratégia é levada ao extremo quando o criador e coordenador do MESP compara professores a estupradores.

No esforço em criminalizar o trabalho docente e promover censura, o MESP, além dos projetos de lei em tramitação e a despeito de decisão monocrática do STF afirmando a inconstitucionalidade do Programa do MESP (BRASIL, 2016), oferece a pais e estudantes modelos prontos de Notificação Extrajudicial para serem entregues a professores e à direção escolar. No site do MESP, encontra-se: "Uma das formas de proteger seu filho contra a doutrinação é notificar o professor e a escola, para que se abstenham de adotar determinadas condutas, sob pena de responder pelos danos que vierem a causar" (ESCOLA SEM PARTIDO, 2020g, grifo do autor). No mesmo link é possível realizar o download de três modelos de notificação (individual endereçada ao professor, individual endereçada à direção e coletiva endereçada à direção), praticamente idênticas. Trata de um conjunto de ameaças (de processo, de exposição pública, de incômodos) dirigidas aos professores e às escolas (por terem, segundo a notificação, responsabilidade solidária), que afirmam o quão fácil e barato é mover um processo contra qualquer pessoa no Brasil contemporâneo. No modelo de notificação extrajudicial direcionada diretamente ao professor, encontra-se:

4. Sob a falsa alegação de incentivar o exercício da cidadania por parte dos estudantes, não são poucos os docentes que abusam da sua autoridade e ascendência sobre eles para incitá-los a participar de atos políticos [...]

5. Há, ainda, os professores que, a pretexto de combater o "preconceito", a discriminação, a homofobia, o machismo, a AIDS etc., se intrometem ilegalmente na formação moral dos alunos [...]

7. Além de covardes e antiéticas, as condutas descritas constituem atos ilícitos [...]

8. Professores que abusam da sua liberdade de ensinar em prejuízo dos direitos acima referidos expõem a si mesmos e às instituições em que trabalham ao risco de ser processados e conde- nados a indenizar os danos sofridos pelos alunos e seus pais. 0 prazo para o ajuizamento dessas ações varia, conforme o caso, de 3 a 5 anos após a ocorrência do dano.

9. A Lei 9.099/95, que dispõe sobre os Juizados Especiais Cíveis e Criminais, facilita bastante o ajuizamento dessas ações. Dependendo do valor da causa, os pais nem sequer precisam estar representados por advogado: basta redigir uma petição demonstrando ao juiz a ocorrência do dano, e pedir a condenação dos réus (o professor e/ou a escola) a repará-lo mediante o pagamento de determinada soma em dinheiro. E é de graça [...]

15. É certo que Vossa Senhoria encontrará, em documentos e diretrizes oficiais, fundamento para que professores introduzam esses temas em suas aulas. Asseguro-lhe, no entanto, que nada disso tem valor diante do direito dos alunos - crianças e adolescentes - à intimidade, à dignidade e ao respeito, que consiste, segundo o ECA, na "inviolabilidade da integridade física, psíquica e moral" [...]

20. Informo que meu filho tem ciência da presente notificação e está orientado a reportar-me de forma detalhada as possíveis transgressões aos direitos acima elencados.

21. Uma cópia desta notificação está sendo encaminhada à direção do (nome da instituição de ensino), que responderá solidariamente pela reparação dos danos que Vossa Senhoria porventura vier a causar, no exercício de suas funções. (ESCOLA SEM PARTIDO, 2020g).

No preâmbulo do documento, em uma parte que deve ser retirada pelos pais antes do envio, escancara-se o objetivo de gerar constrangimento ao professor e, logo, censurar previamente sua prática. Está disposto: "Ao nosso ver, o item 20 é importante, e deve constar da notificação, ainda que, para poupar seus filhos de um estresse desnecessário, os pais decidam não lhes falar sobre a iniciativa" (ESCOLA SEM PARTIDO, 2020g). No ambiente familiar, da socialização primária, se ensina muito com palavras, mas sobretudo se ensina com ações: a recomendação do MESP aqui é pela mentira e ensina que ela, a mentira, possui um valor ocasional (SAVATER, 1998, p. 92). 
Embora o que se encontra na notificação já ofereça condições para afirmar que o MESP mobiliza uma campanha de ódio contra professores e contra o pensamento científico (salvo quando está em acordo com a opinião familiar), é em um texto de 30 de dezembro de 2016, assinado por Nagib e disponível no site do MESP e intitulado "Mensagem de fim de ano do coordenador do Escola sem Partido ao militante disfarçado de professor" (ESCOLA SEM PARTIDO, 2017), no qual se escancara a estratégia de censura prévia, perseguição e amedrontamento de professores e professoras. Na mensagem, o coordenador afirma que, em razão das ações do MESP, a inserção de temas que desagradam as famílias e que compreenderiam o que o movimento chama de doutrinação e propaganda "estão se tornando uma atividade de alto risco. A cada dia mais gente fica sabendo quem você é e o que você faz no segredo das salas de aula" (ESCOLA SEM PARTIDO, 2017). Isso significa, então, que os professores correm o risco de serem alvos de inúmeros processos: "Agora, pense no número de estudantes e pais que podem se sentir lesados pelas suas práticas abusivas ao longo desses três anos, e calcule o tamanho do risco a que você está se expondo e expondo as escolas onde trabalha." (ESCOLA SEM PARTIDO, 2017). Enfatiza que um professor assim processado terá muita dificuldade em garantir, como professor, a sua subsistência: “É por isso que professores com o seu perfil passarão a encontrar cada vez mais dificuldade para arrumar emprego." (ESCOLA SEM PARTIDO, 2017). Após isso, reafirma a facilidade que é, de acordo com as leis brasileiras, processar outra pessoa por danos morais: "Se você soubesse como é fácil, no Brasil, processar outra pessoa, ficaria bastante preocupado." (ESCOLA SEM PARTIDO, 2017). O coordenador do MESP é ciente de que não há base legal para suas afirmações. Então, deixa explícito que o objetivo é tão simplesmente a censura, o constrangimento, produzir um clima tal que faça com que os professores não estejam dispostos a todo o incômodo que um processo judicial e a exposição pública como suposto doutrinador implica. É por isso que Nagib afirma, quase ao fim de sua mensagem: "É claro que algumas dessas ações podem vir a ser julgadas improcedentes; mas até isso acontecer, você já terá tido um bocado de aborrecimentos e despesas. 0 simples fato de ser processado já é uma 'condenação'” (ESCOLA SEM PARTIDO, 2017, grifo do autor). 0 que o MESP quer é atropelar a legislação e instaurar um tribunal permanente de execração pública de intelectuais que ousam pensar para além dos limites estreitos do que o MESP e os demais grupos neoconservadores entendem como a verdade. É nesse espírito que finaliza sua mensagem: “De minha parte, continuarei me esforçando para que molestadores empedernidos como você sejam expelidos do sistema. Desejo-lhe, portanto, um 2017 cheio de denúncias e processos [...] Sem o menor respeito ou admiração, Miguel Nagib" (ESCOLA SEM PARTIDO, 2017). O desejo em "expelir" denuncia o fechamento para tudo o que é "outro".

As propostas dos grupos neoconservadores, mesmo que não consolidadas em leis, têm força de lei, são lei efetiva, porque se verificam na prática (LÖWY, 2015), muito em razão da força violenta com que esses grupos agem: processando professores apenas para criar transtornos, confrontando professores nas entradas e saídas de escolas, expondo ao público em redes sociais aulas ou atividades sugeridas pelos professores etc. Uma das mais drásticas consequências das ações do MESP é a internalização da censura por parte de professores, especialmente na educação básica. Tal situação se agrava se considerarmos que o Projeto de Lei no 246/2019 (BRASIL, 2019), ainda em tramitação, dispõe sobre a gravação de aulas. Antes mesmo de o projeto ser discutido em sessões da Câmara, o MESP entende-o como vigente e disponibilizou, para seus apoiadores, um modelo de petição para que os estudantes possam, em escolas públicas, gravar o áudio das aulas que participam. 
No preâmbulo, o MESP manifesta inconformismo com o fato de que o Ministério Público não abrace sua causa e afirma: "Já que o Ministério Público não faz nada, o ESP decidiu fazer alguma coisa pelas vítimas dos abusos praticados por militantes disfarçados de professores." (ESCOLA SEM PARTIDO, 2019). 0 texto da petição procura, em alguns momentos sustentar o argumento de que o objetivo da gravação é garantir o direito dos estudantes a reverem a lição. Entretanto, a ênfase da petição está no suposto direito dos pais de controlar e, se necessário, censurar e processar, os professores:

6. Já o primeiro impetrante, na condição de pai do segundo, tem o direito líquido e certo de 'ter ciência do processo pedagógico' vivenciado por seu filho, o que compreende o direito elementar de saber o que, efetivamente, está sendo ensinado na escola.

\section{$[\cdots]$}

9. Ora, é evidente que o segundo impetrante usuário direto do serviço - não possui a experiência e a maturidade necessárias para avaliar se essa garantia constitucional está sendo observada pela escola. Pelo contrário: o estudante, quase sempre, é 'cúmplice' do professor 'camarada', mas negligente, que desperdiça o tempo precioso das aulas com assuntos estranhos ao conteúdo programático, poupando-se do esforço de lecionar sua disciplina, e poupando os alunos do indispensável mas, para a esmagadora maioria, nada prazeroso estudo da matéria. É o conhecido 'pacto da malandragem', no qual o professor finge que ensina, e o aluno finge que estuda. Desse modo, seja pela sua inexperiência, seja pela sua proverbial inclinação à 'lei do menor esforço', os alunos não são, definitivamente, bons juízes da qualidade dos serviços prestados pelas escolas. Esse julgamento deve ser feito por aqueles que têm o dever constitucional de assisti-los, criá-los e educá-los: seus pais ou responsáveis. Por isso, não há como deixar de reconhecer-lhes o direito de conhecer e avaliar a qualidade do serviço prestado pelos professores durante as aulas [...]. (ESCOLA SEM PARTIDO, 2017).

Por fim, deixa claro que o objetivo é censurar previamente, se resguardando o direito, ainda, de o fazer mesmo sem o consentimento para produzir provas para eventuais futuros processos:

16. Embora pudessem efetuar a gravação ambiental das aulas sem o conhecimento da escola - visto que o STF reconhece a licitude de tal conduta ao afirmar a validade das provas obtidas com o uso desse recurso -, os impetrantes entendem que a gravação realizada de forma ostensiva, além de respeitar a relação de confiança que deve existir entre a família e a escola, tem o condão de inibir a prática de abusos, por parte de professores ativistas e militantes que usam a sala de aula para promover suas próprias preferências ideológicas, religiosas, morais, políticas e partidárias, em afronta aos direitos constitucionais dos estudantes e seus pais ou responsáveis. Cientes de que estão sendo gravados, esses professores tenderão a ser mais cuidadosos e moderados no uso da palavra, evitando problemas para si mesmos e para as escolas onde lecionam. (ESCOLA SEM PARTIDO, 2017).

Fica clara que a postura do MESP, como manifestação de um movimento neoconservador reacionário, se dirige contra aqueles que, por dever ético e profissional, questionam as coisas do mundo, ou seja, põem em dúvida as certezas e, ao fazerem isso, provocam desconforto. Como aquilo que defende não compreende lei, salvo pela enviesada leitura que promove, procura coagir, perseguir e desestimular professores e professoras por meios extrajudiciais, com o explícito objetivo de causar incômodo e destruir reputações. O MESP procura, por meio de seus discursos, práticas e proposições (PLs, notificações e petições), oferecer para todos os intelectuais que não se curvam à sua estreita visão de mundo a acusação que Meleto e seus comparsas ofereceram ao rei de Atenas no inverno de 400 a.C.

\section{Conclusões}

Meleto, poeta ressentido e principal acusador de Sócrates, afirmava também que "Sócrates persuadia a seus discípulos de que ele os tornava mais sábios que seus pais, assim destruía neles o respeito filial" (MOURA, 2017, 
67). Não foi a primeira vez que Sócrates havia sido acusado disso; Aristófanes (1967), em As nuvens, já o havia feito. Segundo Platão, o próprio Sócrates, sem rancor, em sua defesa diante dos juízes da cidade, mencionou o dramaturgo no início de sua exposição: "Tal é, mais ou menos, a acusação: e isso já vistes, vós mesmos, na comédia de Aristófanes, onde aparece, aqui e ali, um Sócrates que diz caminhar pelas ares e exibe muitas outras tolices, das quais não entendo nem muito, nem pouco." (PLATÃO, 2017, p. 21). Apesar de o discurso de Sócrates ser um libelo precoce da liberdade de pensamento e da dignidade do ser humano, o filósofo foi condenado pela cidade, sob a acusação de corromper a juventude e negar os deuses, à morte por ingestão de cicuta. Sócrates foi vítima da tradição, dos medos daqueles que não estavam dispostos aos perigos do novo, aos perigos do pensamento livre. Foi vítima de um movimento reacionário que fez uso dos instrumentos da democracia grega para condená-lo à morte.

É possível estabelecer alguma relação, no discurso e nas práticas, entre a forma do anti-intelectualismo que processou e condenou o filósofo grego e a atual forma do anti-intelectualismo, neoconservador com afluentes neoliberais e neofascistas, que persegue professores, comparando-os aos criminosos mais execrados pela opinião pública, como, por exemplo, estupradores? A resposta para essa questão é positiva. Não se está negando as diferenças entre os acusadores de Sócrates e os perseguidores de professores. 0 que está se afirmando aqui é que ambos compartilham de uma recusa ao pensamento, de uma recusa à pergunta e de um ressentimento contra aqueles que se arriscam a perguntar, que procuram se desvencilhar das correntes e sair da caverna, que buscam olhar o mundo para além das possibilidades dadas e que provocam os seus contemporâneos a fazer o mesmo. Reafirma-se o argumento, portanto, de que o anti-intelectualismo acompanha o desenvolvimento da tradição ocidental não como um elemento que lhe é paralelo, mas que faz parte de sua própria tendência e, por vezes, é a tendência dominante. No caso brasileiro, o MESP é uma radicalização da tendência anti-intelectual que se projeta sobre a Educação e direciona para os professores e professoras seu reacionarismo.

\section{REFERÊNCIAS}

ADORNO, T. Educação e emancipação. Petrópolis, RJ: Paz e Terra, 1995.

AGAMBEN, Giorgio. Estado de exceção: o poder soberano e a vida nua. Tradução: Iraci Poletti. São Paulo: Boitempo, 2004.

APPLE, Michael W. The politics of official knowledge: does a national curriculum make sense? Teachers College Record, v. 95, n. 2, p. 222-241, 1993. Disponível em: https://www.researchgate. net/publication/247948482_The_Politics_of_ Official_Knowledge_Does_a_National_Curriculum Make_Sense. Acesso em: 06 jun. 2020.

ARENDT, H. A vida do espírito. Trad. de C. A. R. de Almeida. 6. ed. Rio de Janeiro: Civilização Brasileira, 2017.

ARENDT, H. Eichmann em Jerusalém. São Paulo: Companhia das Letras, 1999.

ARENDT, H. Entre o passado e o futuro. São Paulo: Perspectiva, 2016.

ARENDT, $\mathrm{H}$. The origins of totalitarianism. New York: Harcount, Brace \& Co., 1973.

ARISTÓFANES. As nuvens. São Paulo: Difusão Europeia do Livro, 1967.

ATAÍDE, T. A morte de Sócrates. In: PLATÃO. Apologia de Sócrates. Rio de Janeiro: Nova Fronteira, 2017. p. 7-14.

BERCOVICI, Gilberto. Soberania e constituição: para uma crítica ao constitucionalismo. São Paulo: Quartier Latin, 2004.

BIESTA, Gert. Para além da aprendizagem: educação democrática para o futuro humano. Belo Horizonte: Autêntica, 2017.

BOBBIO, Norberto. Liberalismo e democracia. 6. ed. São Paulo: Brasiliense, 1997.

BRASIL. Câmara dos Deputados. Projeto de Lei no 7.180, de 24 de fevereiro de 2014. Brasília, DF, 2014. Disponível em: http://www.camara.gov.br/ proposicoesWeb/fichadetramitacao?idProposic ao=606722. Acesso em: 15 maio 2017. 
BRASIL. Supremo Tribunal Federal. Ação Direta de Inconstitucionalidade 5537/AL. Relator: Ministro Roberto Barroso, 30 de maio de 2016. Disponível em: http://www.stf.jus. br/portal/processo/verProcessoAndamento. asp $?$ numero $=5537 \&$ classe $=$ ADI $-\mathrm{MC} \&$ codigoClass $\mathrm{e}=0$ \&origem=JUR\&recurso=0\&tipoJulgamento $=\mathrm{M}$. Acesso em: 12 mar. 2020.

BRASIL. Câmara dos Deputados. Atividade Leg islativa. Transmissões. Arquivo Sonoro. Miguel Nagib. Câmara dos Deputados. Brasília, DF, 2017. Disponível em: http://imagem.camara.leg.br/ internet/audio/Resultado.asp?txtCodigo $=58813$. Acesso em: 03 mar. 2020.

BRASIL. Câmara dos Deputados. Projeto de Lei no 246, de 21 de fevereiro de 2019. Institui o "Programa Escola sem Partido". Brasília, DF, 2019. Disponível em: https://www.camara.leg.br/ proposicoesWeb/fichadetramitacao?idProposic ao=2190752. Acesso em: 03 mar. 2020.

CALLEGARIS, Contardo. 0 que é um conservador? Folha de S.Paulo, São Paulo, 11 jul. 2019. Disponível em: https://www1.folha.uol.com.br/colunas/ contardocalligaris/2019/07/quem-e-conservador. shtml. Acesso em: 10 mar. 2020.

COSTA, Jurandir Freire. A ética e o espelho da cultura. 2. ed. Rio de Janeiro: Rocco, 1995.

DIAS, Rosa Maria. Nietzsche educador. 2. ed. São Paulo: Scipione, 1993.

DOCUMENTO DA Secretaria de Educação de RO manda recolher de escolas "Macunaíma" e mais 42 livros; secretário diz ser "rascunho". G1, $06 \mathrm{fev}$. 2020. Disponível em: https://g1.globo.com/ro/ rondonia/noticia/2020/02/06/documento-dasecretaria-de-educacao-de-ro-manda-recolher-deescolas-macunaima-e-mais-42-livros-secretariodiz-ser-rascunho.ghtml. Acesso em: 03 mar. 2020.

ENTREVISTA de Jair Bolsonaro ao Jornal Nacional, 2018. 1 vídeo (10 min.). Disponível em: https:// www.youtube.com/watch?v=3k0Q9WFoliw. Acesso em: 10 de março de 2020.

ESCOLA sem Partido, 22 ago. 2017.1 vídeo (1 min.). Publicado pelo canal Jornal da Clube. Disponível em: https://www.youtube.com/watch?v=Cf3zjFt8us. Acesso em: 09 de março de 2020.

ESCOLA SEM PARTIDO. Anteprojetos. Brasília, DF, 2020a. Disponível em: http://www. programaescolasempartido.org/anteprojetos. Acesso em: mar. 2020.
ESCOLA SEM PARTIDO. Parecer. Brasília, DF, 2020b. Disponível em: https://www. programaescolasempartido.org/municipal. Acesso em: mar. 2020.

ESCOLA SEM PARTIDO. Faq. Brasília, DF, 2020c. Disponível em: http://www.escolasempartido.org/ faq/. Acesso em: 10 de março de 2020.

ESCOLA SEM PARTIDO. Apresentação. Brasília, DF, 2020 d. Disponível em: http://www. escolasempartido.org/apresentacao/. Acesso em: jan. 2020.

ESCOLA SEM PARTIDO. Quem somos. Brasília, DF, 2020e. Disponível em: http://escolasempartido. org/quem-somos/. Acesso em: jan. 2020.

ESCOLA SEM PARTIDO. Quero denunciar. Brasília, DF, 2020f. Disponível em: http://www. escolasempartido.org/quero-denunciar/. Acesso em: 07 mar. 2020.

ESCOLA SEM PARTIDO. Artigos e vídeos. Notificação Extrajudicial. Brasília, DF, 2020g. Disponível em: http://www.escolasempartido.org/ artigos-e-videos/notificacao-extrajudicial-armadas-familias-contra-a-doutrinacao-nas-escolas/. Acesso em: 05 mar. 2020.

ESCOLA SEM PARTIDO. Artigos e vídeos. Mensagem de fim de ano do coordenador do Escola sem Partido ao militante disfarçado de professor. Brasília, DF, 2017. Disponível em: http:// www.escolasempartido.org/artigos-e-videos/ mensagem-de-fim-de-ano-docoordenador-doescola-sem-partido-ao-militante-disfarcado-deprofessor/. Acesso em: 05 mar. 2020.

ESCOLA SEM PARTIDO. Blog. Escola sem Partido disponibiliza modelo de petição para garantir direito de gravar aulas. Brasília, DF, 2019. Disponível em: http://www.escolasempartido.org/ blog/escola-sem-partido-disponibiliza-modelode-peticao-para-garantir-direito-de-gravar-aulas/. Acesso em: 13 mar. 2020.

GARGARELA, Roberto. Los fundamentos legales, de la desigualdad, el constitucionalismo na América. Madrid: Siglo XXI, 2005.

GUILHERME, A. A.; PICOLI, B. A. Neoliberalism and education in the global south: a new form of imperialism. In: NESS, I.; COPE, Z. (ed.). The Palgrave encyclopedia of imperialism and anti-imperialism. Palgrave Macmillan, Cham, 2019. Disponível em: https://doi.org/10.1007/978-3319-91206-6_144-1. Acesso em: 02 mar. 2020. 
GUILherme, A. A.; PICOLI, B. A. Escola sem Partido: elementos totalitários em uma democracia moderna - uma reflexão a partir de Arendt. Revista Brasileira de Educação [online], v. 23, 2018. Disponível em: https://www.scielo.br/pdf/rbedu/ v23/1809-449X-rbedu-23-e230042.pdf. Acesso em: 03 mar. 2020.

KANT, I. Resposta à questão: o que é esclarecimento? Trad. de M. Pugliese. Cognitio, São Paulo, v. 13, n. 1, p. 145-154, jan./jun. 2012.

KONDER, Leandro. Introdução ao Fascismo. Rio de Janeiro: Graal, 1977.

LÉVINAS, Emanuel. Algumas reflexões sobre a filosofia do hitlerismo. In: DAVIDOS, A.; LEVINAS, E.; MUSSIL, R. Reflexões sobre o nacional-socialismo. Belo Horizonte: Âyné, 2016. p. 45-69.

LILA, Mark. A mente naufragada: sobre o espirito reacionário. Trad. Clóvis Marques. Rio de Janeiro: Record, 2018.

LÖWY, M. Conservadorismo e extrema-direita na Europa e no Brasil. Serviço Social e Sociedade, n. 124, p. 652-664, out./dez. 2015.

MCLAREN,P.; FARAHMANDPUR, R. The globalization of capitalism and the new imperialism: notes towards a revolutionary critical pedagogy. Review of Education, Pedagogy, and Cultural Studies, v. 23, n. 3, p. 271-315, 2001.

MOURA, M. L. de. Apêndice. In: PLATÃO. Apologia de Sócrates. Edição Especial. Rio de Janeiro: Nova Fronteira, 2017. p. 59-84.

NIETZSCHE, F. W. Sobre o futuro dos nossos estabelecimentos de ensino. In: SOBRINHO, N. C. M (org.). Escritos sobre educação. 5. ed. Rio de Janeiro: PUC-Rio, 2011. p. 53-191.

NUNES, D. P. A Imaginação constitucional brasileira e o mito da atuação contramajoritária: conferências nacionais de políticas públicas e a concretização de direitos de minorias por poderes eleitos. Revista Publicum, Rio de Janeiro, v. 5, n. 1, p. 167-191, 2019.

PENNA, F. A.; SALLES, D. C. A dupla certidão de nascimento do Escola Sem Partido: analisando as referências intelectuais de uma retórica reacionária. In: MUNIZ, A. C.; LEAL, T. B. (org.). Arquivos, documentos e ensino de história: desafios contemporâneos. Fortaleza: EdUECE, 2017. p. 13-38.

PLATÃo. Apologia de Sócrates. Rio de Janeiro: Nova Fronteira, 2017.

PLATÃO. A República. Livro VII. Tradução de Enrico Corvisieri. São Paulo: Nova Cultural. 2000. (Coleção Os Pensadores).

SALLES, L. L. B. M. Sócrates e o processo político que o condenou ao suicídio. Prometheus [online], v. 11, n. 31, 2019. Disponível em: https://seer.ufs. br/index.php/prometeus/article/view/10680. Acesso em: 27 fev. 2020.

SANTOS, J. P. M. dos. Justiça constitucional e a sua função contramajoritária: da limitação à sua legitimação. Revista de Direito Constitucional e Internacional, v. 27, n. 116, p. 107-132, 2019. Disponível em: https://www. tjdft.jus.br/institucional/biblioteca/servicos-eprodutos/revistas-juridicas/revista-de-direitoconstitucional-e-internacional. Acesso em: 25 fev. 2020.

SAVATER, F. 0 valor de educar. São Paulo: Martins Fontes, 1998.

SGARBOSSA, F. S. Et al. Uma crítica à objeção contramajoritária ao controle judicial de constitucionalidade. In: SIMPÓSIO NACIONAL DE DIREITO CONSTITUCIONAL, 10., 2012, Curitiba. Anais eletrônicos [...]. Curitiba: ABDConst, 2012. p. 132-151. Disponível em: http://www.abdconst. com.br/anais2/ObjecaoLuis.pdf. Acesso em: 25 fev. 2020.

STANLEY, Jason. Como funciona o fascismo: a política do "nós" e "eles". Trad. Bruno Alexander. Porto Alegre: L\&PM, 2018.

TURCHI, Maria Zaira. Literatura e antropologia do imaginário. Brasília, DF: Editora da Universidade de Brasília (UnB), 2003.

Recebido em: $14 / 03 / 2020$

Aprovado em: 29/05/2020 